\title{
Clinical supervision in nursing - strategy for knowledge and quality of care
}

\author{
António Luís Rodrigues Faria de Carvalho ${ }^{1}$
}

The demands placed on health professionals, mainly on nurses, are varied and highly complex. We live with changes in lifestyles, an increase in chronic diseases and an increasingly advanced age, raising the need to monetize resources and guarantee excellence of care. These factors, among many others, impel health professionals to think about their practice and develop strategies that ensure their personal and professional development.

The increasing complexity of health problems has highlighted the interest in understanding the implications of the concepts of multidisciplinarity, interdisciplinarity and transdisciplinarity in care, thereby resulting in the need to ensure strategies for developing the knowledge and the discipline of nursing.

The importance of quality in care is increasingly emphasized, as well as the recognition that health professionals need ongoing support to maintain and improve their practice. In this context, clinical supervision in nursing has been considered as a supportive mechanism for nurses' practice and care safety and quality, thereby constituting itself as a guarantee for all citizens using health services.

The operationalization of a clinical supervision model in nursing, supported by the context in which it will be developed, therefore on the nurses' needs, is an effective way of developing professional practice and knowledge, assisting nurses on learning from each other, being mutually supportive, recognize and be recognized by others, as well as moderating concern and anxiety about the functions they perform. Simultaneously, the existence of a clinical supervision model in nursing influences the learning process of nursing students in a positive way by promoting and implementing the decision-making process.

Although the literature points to the existence of several models that can support the implementation of clinical supervision in nursing, the importance of developing a contextualized model is defended. In this model, the process of implementing clinical supervision in nursing must be formalized with the whole structure of the services and the institution, ensuring participation and involvement of everyone. The work should be started with the identification of nurses' needs and training about the concepts, objectives and strategies to be followed. After defining the clinical supervision model in nursing to be implemented, it is important to select supervisors, constitute the supervisory teams and organize the agenda of regular meetings. The work to be performed should produce answers to the needs expressed by the supervisory teams, developing individual or collective, direct or indirect strategies, for the personal and professional development of nurses.

By considering that it is a priority to create quality assurance systems in health that integrate clinical supervision in nursing and that it is relevant to produce scientific evidence that demonstrates the relationship between clinical supervision and the safety and quality of care, it is crucial that we develop investigation projects related to its implementation.

This research-action environment, where nursing knowledge is developed and a high-quality practice is ensured, is an important bet to be disseminated, which will contribute to a more meaningful nursing for the people.

\footnotetext{
${ }^{1}$ Escola Superior de Enfermagem do Porto. Section Editor of the Rev Rene. Porto, Portugal. 